\title{
American Pediatric Society Presidential Address 2003: The Failure of Ockham's Razor in 21st Century Pediatrics
}

\author{
RUSSELL W. CHESNEY \\ Department of Pediatrics, University of Tennessee Health Science Center, Memphis, Tennessee, 38103, U.S.A.
}

It has been a distinct honor to be the President of the American Pediatric Society (APS), for the year 2002-2003, the 115th year of our society. This new century appears to be an interesting period for academic medicine; especially since the past decade has seen the industrialization of American medicine. As eloquently stated in a recent Commonwealth Fund Task Force on Academic Health Centers: "As a society, we are experiencing a period of revolutionary change in the science and practice of medicine. The pace of advances in medical knowledge is unprecedented, as is the pace of change in the organization and financing of health care services. In the space of a decade, the human genome was mapped, managed care fundamentally altered the delivery of care, and the information revolution fueled the empowerment of health care consumers as never before. Everything in health care seems different" (1). An obvious question arises: how can we adapt to these changes by thought and action? This adaptive response is of critical importance for the future of academic pediatrics and for all members of the APS.

At times, and often in reaction to change, each of us engages in simplistic thought processes in which we seek simple answers to our problems. In doing so we fail to adequately analyze a situation and to realize the complex, interlinking relationships that are inherent in all phases of modern medicine. For example, when asked to justify a given therapy, we cite enthusiastically the results of a study. No matter how large or how well powered, we may fail to appreciate the limitations of the study. Design, patient population, impact of diet, environment, appropriate controls, health habits of the subjects, and a myriad of other factors are all variables to be considered. This simplification of thought reverts to a late medieval school of philosophy initially called nominalism, which represents the economy or parsimony of thought known as "Ockham's razor."

Who was Ockham and what is his razor? William of Ockham was born around 1285 A.D. in the village of Ockham in Surrey, England. This tiny village is 25 miles southwest of

Received July 4, 2003; accepted August 7, 2003.

Correspondence: Russell W. Chesney, M.D., University of Tennessee Health Science Center, Department of Pediatrics, Le Bonheur Children's Medical Center, 50 N. Dunlap, Room 306-307, Memphis, TN 38103, U.S.A.; e-mail: rchesney@utmem.edu

DOI: 10.1203/01.PDR.0000125256.53953.48
London (Fig. 1). After joining the Franciscan Order, he studied theology and philosophy at Oxford, where he rapidly emerged as the leading medieval English philosopher. His extensive writings profoundly influenced theologians and philosophers during the 14th and early 15 th centuries (2). His theories, e.g. empiricism, also greatly influence modern philosophic thought (3). A highly original thinker, he struggled with the inconsistencies between the teachings of Aristotle and those of St. Thomas Aquinas. Ockham separated theology, which he felt was based on faith, from philosophy, for which he sought a logical basis. He extensively rejected the proofs of St. Thomas for the existence of God, because Ockham hypothesized these proofs could not be formally proven. To him, these proofs could not stand up to precise and logical scrutiny. In modern parlance, Ockham sternly questioned the relations between different objects and gradually developed his razor. He extensively used the razor in his discussions of relationships and of causality; if a situation or relationship has a complex explana-

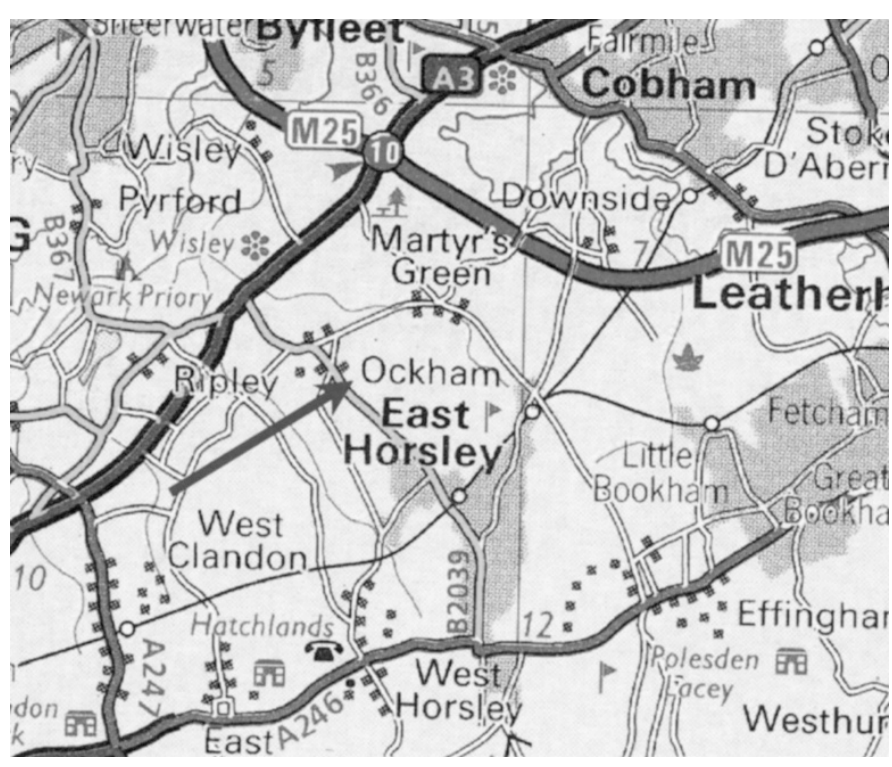

Figure 1. Ockham, England, in the county of Surrey. (Credit: Big Road Atlas Britain, 1991 (C)Automobile Association Developments Limited 2003 CCrown copyright. All rights reserved. License number 399221.) 
tion or a simple explanation, he posited that the simple one is much more likely to be relevant. Ockham thus wielded his razor in his efforts to deny unobservable entities, the existence of which were not evident by experience $(3,4)$.

Ockham expressed this simplifying principle in the following ways: "It is vain to do with more what can be done with less," and "A plurality of things is not to be posited without necessity," and "Entia non sunt multiplicanda praeter necessitatem" (3). A modern translation is "Keep it simple, stupid" (4).

Ockham was not always well received and his theories were controversial. For instance, he was never fully granted either his doctor of philosophy from Oxford or a professorial title, because he failed to "have meaningful accomplishment in research." The Chancellor of Oxford was particularly incensed at Ockham and reported his heretical theories to the Pope in Rome.

In addition, for his rejection of the proofs of God and his insistence on the Franciscan vow of poverty for clergy, Ockham was excommunicated by Pope John XXII. Accordingly, Ockham left Oxford and moved to Munich to serve Emperor Ludwig IV of Bavaria, where he wrote polemics against John, as well as two other Popes, regarding the separation of secular issues from ecclesiasticism (separation of church and state). Ockham died in 1349 in Germany, a victim of the plague (the Black Death) (4). His name is sometimes rendered in the Latin form and spelled "Occam," as is a street in Munich named in his honor.

Ockham's division of the world into a series of absolutes was clearly a break from pre-Socratic, Socratic, and Aristotelian thought. He was a brilliant theologian and philosopher who refused to certify that "things" that were not apparent were proven (3). Many contend that his influence is felt even today.

When we watch TV programs like "Sixty Minutes," "2020," and "Dateline," we embrace Ockham's razor. In these shows, information is usually presented in a one-sided manner without a full examination of the factors that underlie the topic being exposed. In believing the bias of the TV network, we engage in simplistic approaches to causality. Many legal dramas on television or in movies are similar: the stories are presented without regard to the full extent of the situation or a full exposure of the facts in the case. Our presidents chronically wield the razor at each state of the union address. I also contend that we are taught Ockhamic thought processes in school, from the pulpit, by our media, and during all political campaigns.

By this time, everyone in the room is wondering why the APS presidential address should examine medieval philosophical theories. Accordingly, I contend that we need to understand the complexity that underlies our field; we need to fully appreciate the remarkable interplay of forces that impinge on the health of children; we need to reject simplified thought processes and, to the degree we can, we must convey the failure of Ockham's razor as a concept for modern health care to our students, residents, fellows, junior faculty, and, in addition, to our patients and their families. I argue that our role as teachers of and scholars in pediatrics is to understand the complexity of modern medicine, to develop healthy skepticism against oversimplification, and to seek broadly all relevant factors. In effect we all need to be cognizant of the interlinking relationships that both enhance and deter effective action.

Three cogent examples of this complexity are discussed: modern biology, governmental regulation of medicine, and the interplay of forces that define health. In each instance, I will try to convince you that Ockham's razor fails.

First, a remarkable revolution has occurred during the lifetime of nearly everyone in this room that depends upon the application of the laws of physics and the structural relationships of chemistry on the fundamental life science-biology. We are only 50 y removed from the central dogma of the double helix. The living organism is far more complicated than could have been imagined from 1950 to 1970 . A perusal of the list of Nobel Prize winners between 1955 and today illuminates the exponential growth of biologic knowledge based upon physical and chemical principles. A list of contemporary scientific terms makes this point: cell biology, molecular biology, structural biology, receptor biology, non-Mendelian genetics, cell signaling, transplantation biology, tumor biology, oncogenes, functional genomics, functional proteomics, and so on.

Two concepts illustrate the complexity of modern biology. The STAT-JAK system of signaling is key to fundamental cellular processes such as hormone action, apoptosis, activation and repression of transcription pathways, and other cellular actions (Fig. 2) (5). It shows an interlinking panoply of factors. A second example and an unanticipated finding, uncovered in the race to map the human genome, is that the human genome doesn't consist of 100,000 genes, but rather 35,000 to 40,000 genes (6). Figure 3 demonstrates how a complex gene can be responsible for the coding of multiple functional peptides (7). Moreover, we are closely related, in terms of gene homology, to yeast, nematodes, fruit flies, and chimps. Differences in the human genome between Africans and Europeans comprise only $0.1 \%$. As stated by Ingrid Schmidt, "Evolution is characterized by increasing plasticity and redundancy of control systems rather than by an increasing number of genes" (8). Alternative splicing and its multiple protein products are especially important in many clinical situations.

Many of our insights into modern biology and human biology depend upon the exploitation of the field of bioinformatics $(6,8)$. These techniques permit rapid analysis of millions of pieces of data, often from gene and proteome chips, by the simultaneous solving of sophisticated differential equations and interlinking variables. Weiss et al. (9). have noted that "advances in molecular biology now permit complex biologic systems to be tracked at an exquisite level of detail." Figure 4 demonstrates the multiplicity of layers of organization and how they proceed from a biologic level to implications for clinical medicine (9). The information flow is so great, however, that using intuition alone to draw connections is unrealistic. Thus, the need to integrate mathematical biology with experimental biology is greater than ever (9). We require a language that allows the theoretician to communicate with the experimentalist. Perhaps the most useful field of mathematics to aid a contemporary physician is probability, a subject to which few of us are exposed except in a trivial fashion. Norman Fost has mused that, 

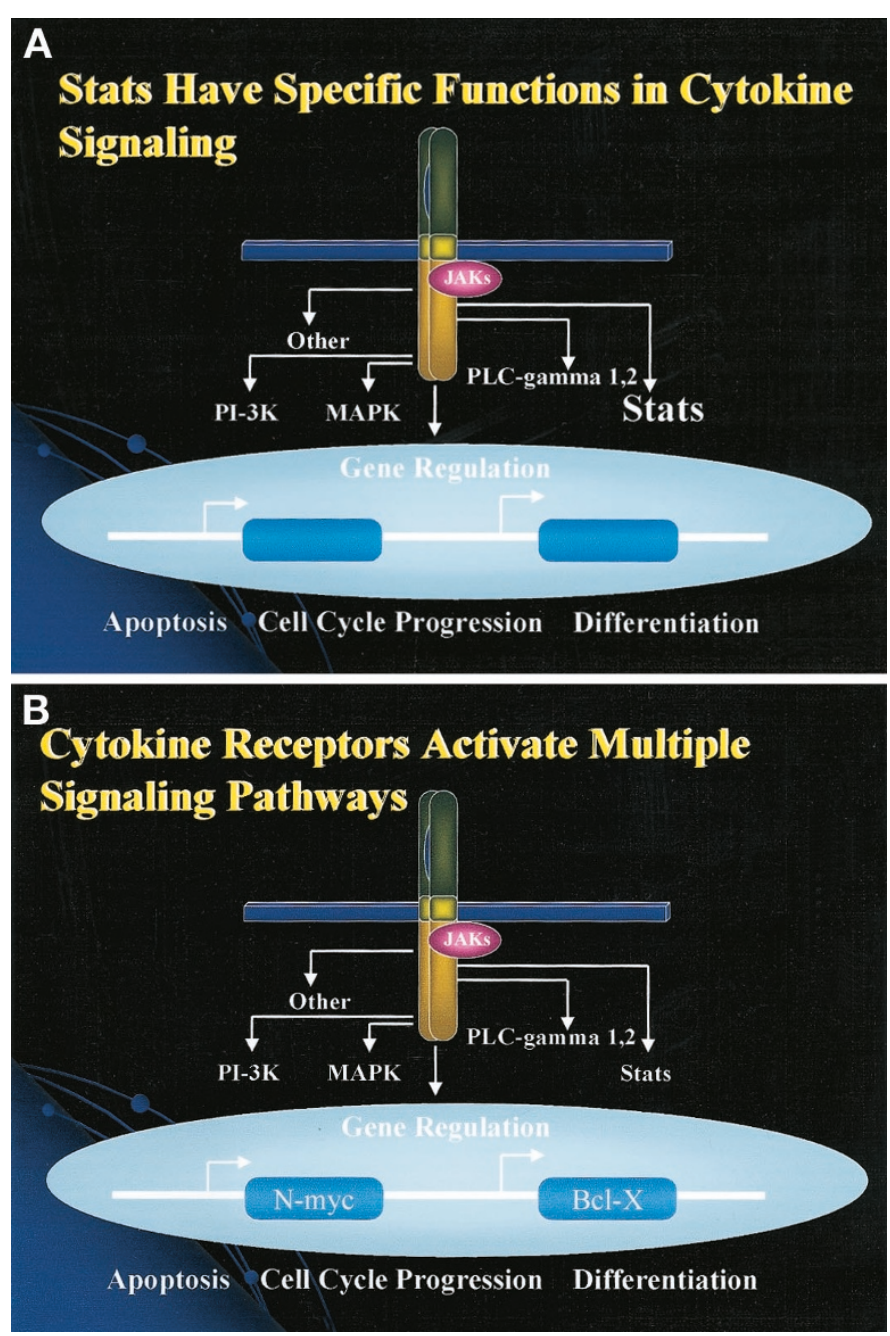

Figure 2. STAT-JAK. (A) Stats have specific functions in cytokine signaling. (B) Cytokine receptors activate multiple signaling pathways. (Ihle J, personal communication.)

in our secondary school education, we could easily spend less time on a 6th century B.C. Greek mathematical set of proofs (known as geometry), and spend more time on the discipline of probability (Fost N, personal communication). An understanding of modern genetics or insight into biologic modeling and epidemiologic research is far more dependent on probability and statistical analysis than on the logic of geometry.

Ockham could not benefit from the knowledge explosion that occurred during the scientific revolution and the age of reason to form his synthesis of philosophy. Nevertheless, modern scientists embrace Ockham's razor when they attribute a biologic finding to a single chemical molecule rather than the interplay of forces. We have all heard how chemical $\mathrm{X}$ is the key to all biologic systems. No wonder we tend to have a molecule of the decade (epinephrine, DNA, cAMP, calmodulin, nitric oxide, etc.). I predict that small interfering RNA will be molecules of this decade, and a hot topic at next year's meeting (10).

Government intrusion into medicine is a complex issue that influences the lives of everyone connected with modern medicine in an all-encompassing and increasingly pervasive fash- ion. Medicaid insures many children, but cannot assure access to physician care. Each of us has paid several thousand dollars into a health insurance plan called Medicare that most of us won't use until after age 65 . We will also need supplemental insurance to be adequately covered. Beginning this year, privacy regulations have become so complex that medical research could be threatened; we await the coming litigations arising from the 1996 Health Insurance Portability and Accountability Act (HIPAA) to more fully perceive the effect of regulations on privacy, which, remarkably, is not a guarantee of the United States Constitution or its amendments. At the same time, we are moving toward computerized medical records that may be transparent in terms of privacy. Government laws (from Congress) or regulations (from the executive branch) commonly result in unintended consequences. I cite three recent examples:

1) After Clinical Laboratory Improvement Amendments (CLIA) regulations were promulgated, I, a nephrologist, could not examine the urine of my patients because of the threat of a $\$ 10,000$ fine and a jail term. A machine "read" the spun urine samples but ignored all casts - red cell, white cell, or mixed. Finally, a waiver mechanism was created, such that previously trained personnel could gain a waiver and examine the urine: casts were again detected in the urine of renal patients and we could consider a diagnosis of glomerulonephritis.

2) We know that most medications have not been tested in children in a fashion sufficient to permit traditional Food and Drug Administration (FDA) labeling. A set of government regulations was passed in 1997, known as the FDA Modernization Act (FDAMA), that required the testing of drugs in children. Recently, our nation faced the prospect that section 111 of FDAMA, which covers this testing, would be suspended. This section covering medication trials in children would fade because of threatened litigation from the Competitive Enterprise Institute. This group took the high moral ground so as to "protect children" (11). Well-directed public outcry and letters to Congress from all major pediatric groups, including the APS, applied pressure to overcome this proposed suspension; however, a recent federal judge's actions again raise this specter. Federal legislation may become necessary.

3) The fee for administration of immunizations, to cover office costs and equipment, was recently reduced by Center for Medicare and Medicaid Services (CMS) from $\$ 10$ to $\$ 3.96$. Accordingly, most private offices could not meet the cost of administration of immunizations to Medicaid-insured children, forcing children to receive their vaccines from local health department clinics. This idea runs counter to Institute of Medicine/AAP/U.S. Public Health Service policies to provide care to children in a "medical home" and the goal of fully immunizing our child population. Moreover, other federal government rulings have, in part, led to vaccine shortages for fear of litigation.

Please do not confuse me with King Canute, who railed against the waves, ordering the tide to recede. I rather want you to realize that embracing Ockham's razor leads to simplistic thinking, which tends to overlook the powerful "law of unintended consequences" (12). 

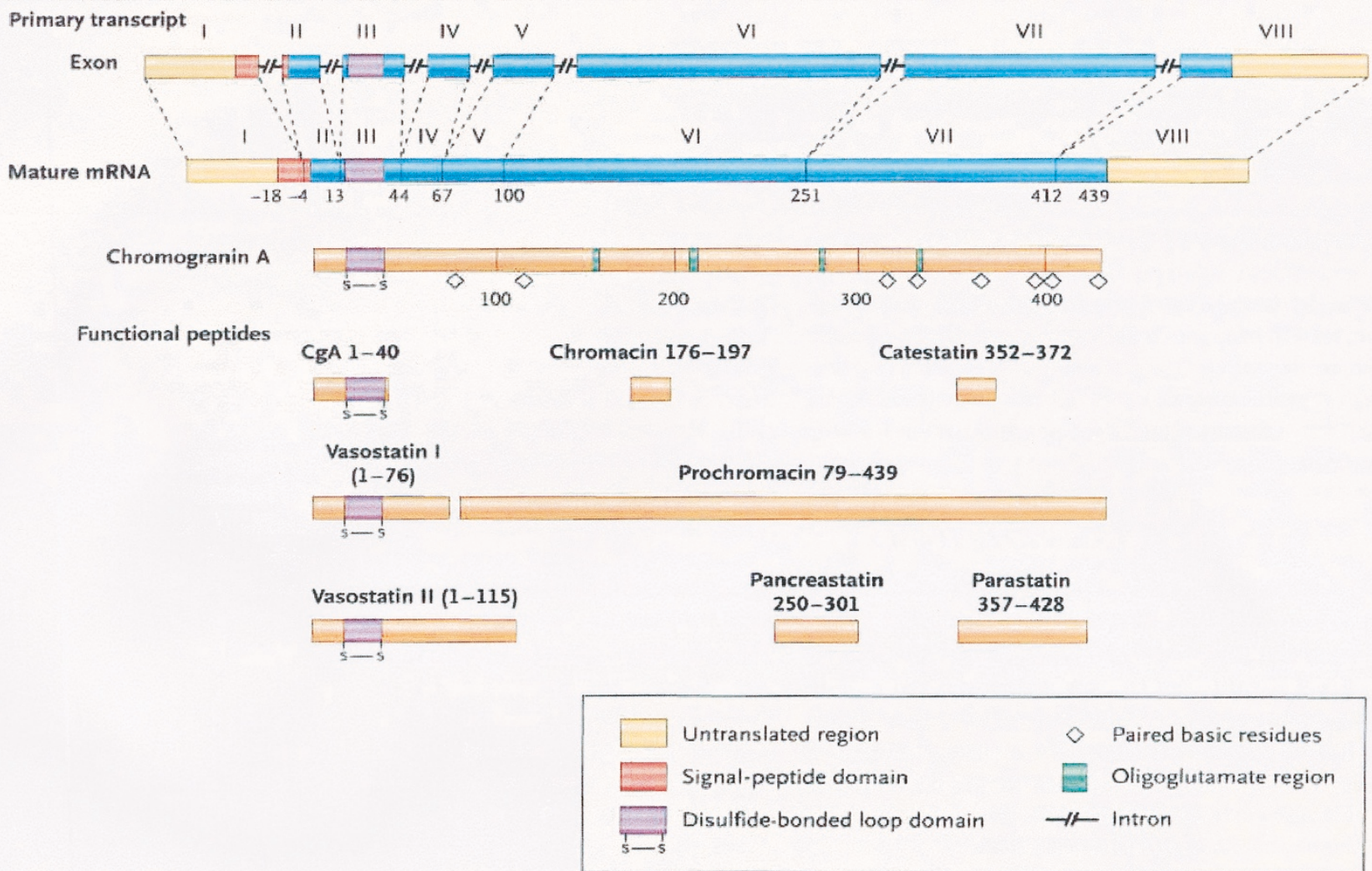

Figure 3. A complex gene can be responsible for the coding of multiple functional peptides. Peptide-encoding regions and putative functional domains of human chromogranin A ( $\mathrm{CgA})$ : Arabic numbers designate amino acids in the mature protein (minus signal peptide). Roman numerals designate exon numbers. The intron-exon structure is not drawn to scale.

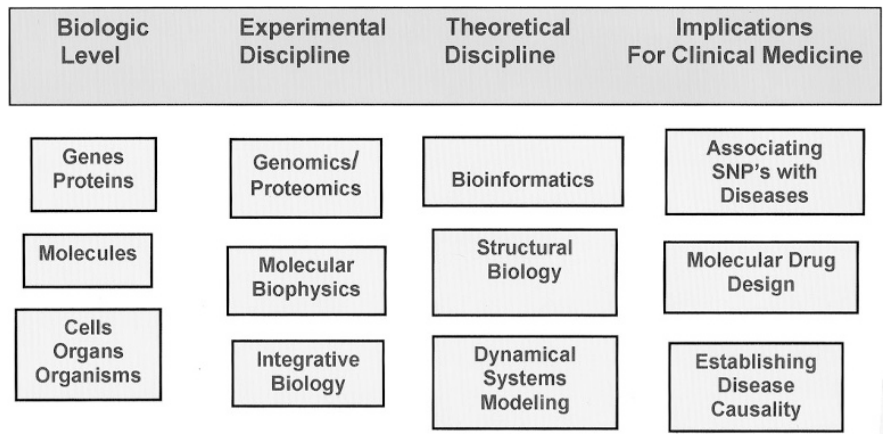

Figure 4. The multiplicity of layers of organization and how they proceed from a biologic level to implications for clinical medicine (9).

Many aspects of governmental intrusion are positive. Our medications are generally well tested, especially compared with some other nations. Web sites such as PubMed and Google provide a vital service to all physicians, particularly as they support life-long learning. Pediatric residents are educated by Federal GME funds. The National Institutes of Health (NIH), National Science Foundation (NSF), Centers for Disease Control (CDC), Agency for Health Services Research and Quality Improvement (AHRQ), and Maternal and Child Health Agency $(\mathrm{MCH})$ represent the research and development efforts of our nation. Moreover, these agencies have contributed in an astonishing fashion to our progress in biomedical, clinical, health outcome, social, and epidemiologic research.

Parenthetically, in our role as advocates for children and as we approach legislators and government agents, we sometimes need to embrace Ockhamism. Our message should be simple and may only present "our side of the story" unfettered by complexities. Perhaps our trainees not only need to learn complexity in thinking but also need to learn selective Ockhamism. This is also true for our political lobbying about child health issues. Hence, the onepage sound bite to pass out to congressmen.

To define health we need to recognize that the health of children is the result of a complex interplay of equally important factors: biology, socioeconomic status, education, environment, and health habits (13). No factor is more or less important and the whole should be examined as a multifaceted issue. The biology of a child consists, in part, of his or her genetic make up, his or her polymorphisms, the mutations present, the ontogeny of enzyme and transport systems, in utero and fetal events beginning with the status of the egg or sperm, the nutritional status of the mother, and exposure to environmental toxins. Culture, ethnicity, and socioeconomic status all influence the expression of disease and access to contemporary and appropriate health care. An important role of education is to overcome superstition, old wives' tales, and Ockhamistic thinking. Each of us has heard a patient, a parent, a grandparent, a neighbor, a reporter, an office worker, and sometimes even a faculty member raise a nonsensical association: "Mohammed Ali developed Parkinson's disease after his house was sprayed by insecticides," "You can only get AIDS from homosexual activity," or, my mother's favorite, "Don't swallow watermelon seeds - they cause appendicitis." Each of us has heard an attending physician suggest, "When you hear hoof 
beats, don't think of zebras." (While horses are more common than zebras, zebras are present everywhere.) That particular truism has returned to haunt each of us.

The role of environmental factors on life expectancy is remarkable. We seem to want to ignore new pollutants and toxins and to embrace war toys that maim and kill. Health is affected by such factors as smoking, adherence to medications, failing to accept our genetic makeup, limiting exercise, and allowing our addictions to dominate us. Our health habits frequently ignore biologic information and rational behavior. Why should anyone smoke cigarettes? William of Ockham would view each of these as separate and unrelated, and would reject the interplay of factors. Unfortunately, many of our patients and their families embrace Ockham's razor: "Immunizations will befoul the ecology of my child's body," "The lack of zinc in the soil around here results in the nephrotic syndrome and edema," "Immunizations cause autism." This list of Ockhamistic aphorisms seems endless.

With the increased penetrance of managed care in our health care system, a concept has emerged that efficient time management using clinical guidelines will permit all physicians, including clinical faculty members, to examine patients more rapidly, thereby enhancing clinical income. Is this the new central mission of a medical school? In view of the complex regulatory systems found in cell biology, the interplay of systems in biomedical research, the extent of state and federal government involvement, concerns over medical errors one hopes will be improved by systems analysis, and the multiplicity of factors that contribute to health, any truncation of time spent with each patient is illogical. Whenever a pediatrician has insufficient time to evaluate a child and to interact with the family of this child, a system of care will need to involve other health professionals lest there be an inadequate response to a given health care demand. We must avoid Okamistic thinking regarding the concept of cookie-cutter care so as to avoid omitting important factors in health.

My challenge to you is to try to understand the complexity of modern medicine, to appreciate the interplay of forces that influence health and access to medical care, and to define our biologic response to medications. We should appreciate that health is biologic, but also environmental, social, economic, and relating to educational status and health habits. Moreover, we need to teach this enlightened view to our students and emphasize skepticism against simplistic claims. We should anticipate unexpected consequences and favor proactive thinking that examines critical factors that have complex interactions.

A few conclusions are appropriate:

- At times we should embrace the razor. It sometimes fits. However, it does not fit modern child health care.

- I fear that I am bashing William of Ockham. He was the world's leading philosopher for a century and a half (3). He was a brilliant thinker who called it as he saw it (14). His insights were limited by the paucity of medieval science. Ockham also was an "empirical" thinker. I speculate that, were he living today, he would appreciate the extent to which we can perceive "things" using informatics, nanotechnology, highresolution microscopy, and data analysis.

- I have focused on U.S. government issues that affect health. The institutions of Canada have different names, but the issues are similar. If anything, government intrusion there is greater or, at least, just as pervasive.

- The excitement of modern biology is palpable. We are truly only limited by our lack of wonder and imagination. Pediatrics will continue to be even more exciting, if we expose and emphasize life-long learning to our students and the value of modern informatics (13).

- If we understand the complexity and diversity of health care, the benefits and limitations of research and its translation to care, and the educational processes, then we can recruit, retain, and work with the very best professionals in our society. I charge all APS members to recognize the fascination and excitement of the complexity of modern academic medicine and to be part of the process by which our students embrace this knowledge.

- If the APS continues to choose members who are critical, skeptical, role models, and scholars who understand the larger interlinked picture, we will thrive.

- I have departed from most presidential addresses both in topic and tone. I can find no evidence of a discussion of medieval philosophy in any previous presidential address (15). I hope I have been somewhat provocative and pointed out daily issues that we all face, but do not always recognize.

Acknowledgments. I have been honored as President of APS and realize that the efforts of recent presidents, the secretarytreasurer, and the staff, especially Kathy Cannon, have enhanced the value of the society for all of us.

\section{REFERENCES}

1. The Commonwealth Fund 2002 Training Tomorrow's Doctors: The Medical Education Mission of Academic Health Centers: A Report of the Commonwealth Fund Task Force on Academic Health Centers. Report no. 516. The Commonwealth Fund, New York

2. Wildner M 1999 In memory of William of Occam. [letter] Lancet 354:1272

3. Copleston F 1963 Late medieval and renaissance philosophy. In: A History of Philosophy. New York, Image Doubleday pp 1-152

4. Williams R 2000 Physicist Anthony Garrett explains the meaning of Ockham's razor. [transcript] Radio National. April 16, 2000

5. Scott MJ, Godshall CJ, Cheadle WG 2002 Jaks, STATs, cytokines, and sepsis. Clin Diagn Lab Immunol 9:1153-1159

6. Chesney RW, Friedman A, Kanto WP, Stanton BF, Stull TL 2002 Pediatric practice and education in the genomic/post-genomic era. J Pediatr 141:453-458

7. Taupenot L, Harper KL, O'Connor DT 2003 The chromogranin-secretogranin family. N Engl J Med 348:1134-1149

8. Schmidt I 2002 Metabolic diseases: the environment determines the odds, even for genes. News Physiol Sci 17:115-121

9. Weiss JN, Qu Z, Garfinkel A 2003 Understanding biological complexity: lessons from the past. FASEB J 17:1-6

10. Ljungman M, Zhang F, Chen F, Rainbow AJ, McKay BC 1999 Inhibition of RNA polymerase II as a trigger for the p53 response. Oncogene 18:583-592

11. Competitive Enterprise Institute 2003 Pediatric drug testing bill could endanger lives. [press release] Competitive Enterprise Institute, Washington, DC, February 28, 2003

12. Chesney RW 2001 Privacy and its regulation: Too much too soon, or too little too late. Pediatrics 107:1423-1425

13. Chesney RW 2001 Joseph W. St. Geme, Jr address 2001: can one have a successful academic career in 2001? Pediatrics 108:1349-1352

14. Beckett D 1994 Biography of William of Ockham. University of Kent at Canterbury, Canterbury, U.K.

15. Pearson HA 1988 The American Pediatric Society: A Century of Progress in Child Health. Yale University Printing Service, New Haven, CT 